\title{
COVID-19 and the Ophthalmology Residency Match: Data from Applicants' Perspectives
}

\author{
Benjamin Steren, BA ${ }^{1} \quad$ Ankur Parikh, BS ${ }^{2}$ Bilal Ahmed, BS ${ }^{3}$ Benjamin Young, MD, MS ${ }^{1}$ \\ Jayanth Sridhar, $\mathrm{MD}^{4}$ Ninani Kombo, MD ${ }^{10}$
}

\footnotetext{
${ }^{1}$ Department of Ophthalmology and Visual Sciences, Yale School of Medicine, New Haven, Connecticut

2 Northeast Ohio Medical University, Rootstown, Ohio

3 University of Toledo College of Medicine, Toledo, Ohio

${ }^{4}$ Bascom Palmer Eye Institute, University of Miami Miler School of Medicine, Miami, Florida
}

J Acad Ophthalmol 2021;13:e73-e77.

\author{
Address for correspondence Ninani Kombo, MD, Department of \\ Ophthalmology and Visual Sciences, Yale School of Medicine, 40 \\ Temple Street, New Haven, CT 06510 \\ (e-mail: Ninani.kombo@yale.edu).
}

\begin{abstract}
Keywords

- COVID-19

- residency

- applications

- student perceptions

Background The coronavirus disease 2019 (COVID-19) pandemic has had a profound impact on medical education, particularly for those applying to residency programs in 2020 to 2021. This study describes the challenges for potential ophthalmology residency applicants so that residency leadership can make informed decisions about changes to the process.

Methods A survey was distributed electronically via social media and medical school ophthalmology interest groups from June 18, 2020 to July 2, 2020 to individuals interested in applying to ophthalmology residency in the United States. Survey questions included demographics and perceived impacts of COVID-19 on ability, confidence, intention to apply, and perceptions toward changes in the application process for the 2020 to 2021 ophthalmology residency application cycle.

Results One-hundred sixteen total responses were received. Eighty-six responses (74\%) were from individuals intending to apply in the 2020 to 2021 application cycle. Most respondents ( $86 \%$ ) felt that their application would be affected by COVID-19 with $51 \%$ feeling less confident. Only four ( $5 \%$ ) felt that they could adequately compile a rank list following a video interview, and over half (51\%) anticipated applying to more programs than they originally intended. Academic plans of seven (8\%) respondents were significantly altered via deferral of application or cancellation of a research year. Thirty-nine (45\%) students reported delayed ophthalmology electives, with less than half $(41 \%)$ feeling that they had adequate clinical exposure to be prepared for residency.

Conclusion The COVID-19 pandemic has had a substantial impact on the 2020 to 2021 ophthalmology residency application cycle. As stakeholders begin to approach this cycle, these findings will help them make effective and informed decisions to create the best overall experience for all involved.
\end{abstract}

received

August 31, 2020

accepted after revision

September 30, 2020
DOI https://doi.org/

10.1055/s-0041-1728759.

ISSN 2475-4757. (c) 2021. The Author(s).

This is an open access article published by Thieme under the terms of the Creative Commons Attribution-NonDerivative-NonCommercial-License, permitting copying and reproduction so long as the original work is given appropriate credit. Contents may not be used for commercial purposes, or adapted, remixed, transformed or built upon. (https://creativecommons.org/ licenses/by-nc-nd/4.0/)

Thieme Medical Publishers, Inc., 333 Seventh Avenue, 18th Floor, New York, NY 10001, USA 
The coronavirus disease 2019 (COVID-19) global pandemic has had a tremendous impact on society, and medical education has been no exception. On March 17, 2020, the Association of American Medical Colleges recommended a suspension of all clinical activities, including the Visiting Student Application Service. ${ }^{1}$ On March 18, 2020, the American Academy of Ophthalmology recommended that ophthalmologists only provide emergency care, causing a $79 \%$ reduction in patient visits. $^{2-4}$ This coincided with the time when hundreds of third and fourth year medical students typically participate in ophthalmology electives. For the majority of these students, exposure to ophthalmology is now limited to a condensed fourth year packed with core rotations, residency applications, and United States Medical Licensing Examination (USMLE) Step preparation.

The Coalition for Physician Accountability subsequently released recommendations that all residency interviews be conducted virtually. ${ }^{5}$ As a result, the Association of University Professors of Ophthalmology (AUPO) has moved interviews virtually and capped interviews to a maximum of 20 per applicant. ${ }^{6,7}$ Furthermore, the AUPO, in conjunction with the San Francisco Match, have extended application submission deadlines, interview dates, and rank list deadlines by several weeks, creating new challenges to consider for applicants and residency programs alike. ${ }^{7}$

To most effectively address these challenges, it will be vital for residency program directors to have as much information as possible about the perspectives and specific challenges faced by this year's applicant pool. Herein, we report a survey of residency applicants, with the aim to provide information to ophthalmology residency directors, medical students, educators, and physicians involved in the mentorship of ophthalmology residency applicants about the effects of COVID-19 and the concerns of the cohort that will be applying during the 2020 to 2021 ophthalmology match cycle.

\section{Methods}

A survey was created using Yale Qualtrics to evaluate the impact of COVID-19 on medical students' ability, confidence, intention to apply, and perceptions toward changes in the application process for the 2020 to 2021 ophthalmology residency application cycle (see eAppendix for full survey). The study was approved by the Yale School of Medicine Institutional Review Board.

The survey was distributed via social media (Twitter, Instagram, Reddit, Discord), two ophthalmology focused podcasts, ${ }^{a}$ and direct outreach to ophthalmology interest groups at US medical schools. The survey was open for completion from June 18, 2020 to July 2nd, 2020. Using the total number of applicants from the 2019 to 2020 match cycle (554), we calculated that a sample size of 82 would be needed for the results to be representative of the total population with a $10 \%$ margin of error at the $95 \%$ confidence level.

\footnotetext{
a Eyes for Ears and Straight from the Cutter's Mouth.
}

\section{Results}

\section{Demographics}

A total of 116 completed survey responses were received (-Table 1). Eighty-six (74.14\%) responses were from individuals applying for the 2020 to 2021 residency application cycle

Table 1 Demographics

\begin{tabular}{|c|c|c|}
\hline Academic stage & & \\
\hline Advanced Clerkship Medical Student & $82.56 \%$ & 71 \\
\hline Research Year Medical Student & $8.14 \%$ & 7 \\
\hline International Medical Graduate & $9.30 \%$ & 8 \\
\hline \multicolumn{3}{|l|}{ Gender } \\
\hline Male & $61.18 \%$ & 52 \\
\hline Female & $35.29 \%$ & 30 \\
\hline Prefer not to answer & $3.53 \%$ & 3 \\
\hline \multicolumn{3}{|l|}{ Race } \\
\hline White & $43.96 \%$ & 40 \\
\hline Asian & $40.66 \%$ & 37 \\
\hline Black or African American & $5.49 \%$ & 5 \\
\hline Hispanic or Latino & $5.49 \%$ & 5 \\
\hline Other & $3.30 \%$ & 3 \\
\hline American Indian or Alaska Native & $1.10 \%$ & 1 \\
\hline Native Hawaiian or Pacific Islander & $0.00 \%$ & 0 \\
\hline \multicolumn{3}{|l|}{ Geographic region } \\
\hline South & $30.00 \%$ & 24 \\
\hline Midwest & $21.25 \%$ & 17 \\
\hline West & $18.75 \%$ & 15 \\
\hline Northeast & $17.50 \%$ & 14 \\
\hline International Medical Graduate & $10.00 \%$ & 8 \\
\hline \multicolumn{3}{|l|}{ Medical school type } \\
\hline MD granting institution-US allopathic & $86.05 \%$ & 74 \\
\hline $\begin{array}{l}\text { Other, ex medical school } \\
\text { completion outside the United States }\end{array}$ & $8.14 \%$ & 7 \\
\hline DO granting institution-US osteopathic & $5.81 \%$ & 5 \\
\hline \multicolumn{3}{|l|}{ Home Ophthalmology Department } \\
\hline Yes & $82.56 \%$ & 71 \\
\hline No & $17.44 \%$ & 15 \\
\hline \multicolumn{3}{|l|}{ Top 40 medical school } \\
\hline No & $66.28 \%$ & 57 \\
\hline Yes & $32.56 \%$ & 28 \\
\hline Prefer not to answer & $1.16 \%$ & 1 \\
\hline \multicolumn{3}{|l|}{ Ophthalmology elective } \\
\hline $\begin{array}{l}\text { Plan to complete an } \\
\text { ophthalmology elective }\end{array}$ & $50.00 \%$ & 52 \\
\hline $\begin{array}{l}\text { Completed an ophthalmology } \\
\text { elective-home institution }\end{array}$ & $36.54 \%$ & 38 \\
\hline $\begin{array}{l}\text { Completed an ophthalmology } \\
\text { elective-outside institution }\end{array}$ & $5.77 \%$ & 6 \\
\hline Elective scheduled-outside institution & $7.69 \%$ & 8 \\
\hline
\end{tabular}


(Advanced Clerkship Students, Research Year or International Medical Graduates).

\section{Effects of COVID-19 on Applications, Interviews, and Rank List (- Table 2)}

Most respondents ( $86.04 \%)$ felt that their application would be affected by COVID-19. A majority (51.16\%) felt less confident in their application. Very few (4.65\%) felt that they could adequately assess and complete a rank list through video interviews. Applicants anticipated applying to more programs

Table 2 COVID-19 and applications

\begin{tabular}{|c|c|c|}
\hline Feel like your application is affected? & & \\
\hline Extremely likely & $34.88 \%$ & 30 \\
\hline Moderately likely & $51.16 \%$ & 44 \\
\hline Neither likely nor unlikely & $6.98 \%$ & 6 \\
\hline Moderately unlikely & $3.49 \%$ & 3 \\
\hline Extremely unlikely & $3.49 \%$ & 3 \\
\hline \multicolumn{3}{|l|}{ Positive effects? } \\
\hline No & $39.53 \%$ & 34 \\
\hline Yes & $34.88 \%$ & 30 \\
\hline Unsure & $25.58 \%$ & 22 \\
\hline \multicolumn{3}{|l|}{ Top concerns } \\
\hline Letters of recommendations & $23.67 \%$ & 58 \\
\hline USMLE scores & $14.29 \%$ & 35 \\
\hline Research & $14.29 \%$ & 35 \\
\hline Medical school ranking or reputation & $12.65 \%$ & 31 \\
\hline AOA membership & $11.84 \%$ & 29 \\
\hline Sub-internship evaluations & $10.20 \%$ & 25 \\
\hline Activities and extracurriculars & $8.98 \%$ & 22 \\
\hline MSPE letter & $4.08 \%$ & 10 \\
\hline \multicolumn{3}{|l|}{ Confidence } \\
\hline Less confident & $51.16 \%$ & 44 \\
\hline Neither more or less confident & $37.21 \%$ & 32 \\
\hline More confident & $11.63 \%$ & 10 \\
\hline \multicolumn{3}{|l|}{$\begin{array}{l}\text { Ability of residencies to assess through } \\
\text { video interview }\end{array}$} \\
\hline No & $46.51 \%$ & 40 \\
\hline Unsure & $40.70 \%$ & 35 \\
\hline Yes & $12.79 \%$ & 11 \\
\hline \multicolumn{3}{|l|}{$\begin{array}{l}\text { Ability of create rank list through video } \\
\text { interview }\end{array}$} \\
\hline No & $69.77 \%$ & 60 \\
\hline Unsure & $25.58 \%$ & 22 \\
\hline Yes & $4.65 \%$ & 4 \\
\hline \multicolumn{3}{|l|}{ Number of applications } \\
\hline Apply to more programs & $51.16 \%$ & 44 \\
\hline No effect & $46.51 \%$ & 40 \\
\hline Apply to fewer programs & $2.33 \%$ & 2 \\
\hline
\end{tabular}

(Continued)
Table 2 (Continued)

\begin{tabular}{|c|c|c|}
\hline \multicolumn{3}{|l|}{ Interviews you would accept } \\
\hline Attend more interviews & $77.65 \%$ & 66 \\
\hline Attend the same number & $20.00 \%$ & 17 \\
\hline Attend less interviews & $2.35 \%$ & 2 \\
\hline \multicolumn{3}{|l|}{$\begin{array}{l}\text { How do you feel about a limitation on } \\
\text { the number of interviews a student may } \\
\text { submit? }\end{array}$} \\
\hline Strongly agree & $31.40 \%$ & 27 \\
\hline Agree & $36.05 \%$ & 31 \\
\hline Neither agree nor disagree & $17.44 \%$ & 15 \\
\hline Disagree & $9.30 \%$ & 8 \\
\hline Strongly disagree & $5.81 \%$ & 5 \\
\hline \multicolumn{3}{|l|}{$\begin{array}{l}\text { Plan to ask mentors for a } \\
\text { recommendation }\end{array}$} \\
\hline Yes & $47.06 \%$ & 40 \\
\hline Maybe & $43.53 \%$ & 37 \\
\hline No & $9.41 \%$ & 8 \\
\hline \multicolumn{3}{|l|}{$\begin{array}{l}\text { Three most important factors in } \\
\text { applying to a residency program }\end{array}$} \\
\hline Location & $27.34 \%$ & 73 \\
\hline Likelihood of interview invitation & $22.10 \%$ & 59 \\
\hline Reputation & $18.35 \%$ & 49 \\
\hline $\begin{array}{l}\text { Connection with faculty/mentors at } \\
\text { your institution }\end{array}$ & $10.11 \%$ & 27 \\
\hline Number of residents & $8.61 \%$ & 23 \\
\hline Faculty reputation & $8.24 \%$ & 22 \\
\hline Previous affiliation or collaboration & $5.24 \%$ & 14 \\
\hline Number of fellows & $0.00 \%$ & 0 \\
\hline \multicolumn{3}{|l|}{$\begin{array}{l}\text { What things will make you more com- } \\
\text { fortable assessing a residency program? }\end{array}$} \\
\hline Videos of the residents & $26.78 \%$ & 79 \\
\hline Videos of the faculty & $25.42 \%$ & 75 \\
\hline $\begin{array}{l}\text { Videos highlighting possible living } \\
\text { areas }\end{array}$ & $21.69 \%$ & 64 \\
\hline Videos of the city & $20.34 \%$ & 60 \\
\hline Other & $5.76 \%$ & 17 \\
\hline
\end{tabular}

Abbreviations: AOA, Alpha Omega Alpha; COVID-19, coronavirus disease 2019; MSPE, Medical Student Performance Evaluation; USMLE, United States Medical Licensing Examination.

and accepting more interviews this cycle. Letters of recommendation emerged as the top concern for applicants.

\section{Effects of COVID-19 on Testing, Electives, and Rotations (- Table 3)}

The academic plans of 7 (8.24\%) respondents were significantly altered, either deferring to the next application cycle or cancelling a research year. Home ophthalmology electives were commonly affected by COVID-19, with 39 (45.35\%) students reporting delays or rescheduling. Less than half (41.86\%) felt that they had adequate clinical exposure to be prepared for residency. 
Table 3 Testing, electives, rotations

\begin{tabular}{|c|c|c|}
\hline Activities during the COVID-19 pandemic & & \\
\hline Research & $22.57 \%$ & 65 \\
\hline Virtual electives/lectures & $21.18 \%$ & 61 \\
\hline USMLE preparation & $13.19 \%$ & 38 \\
\hline Volunteer work (related to COVID-19) & $12.50 \%$ & 36 \\
\hline Clinical rotations & $10.76 \%$ & 31 \\
\hline Assisting family members or loved ones & $9.72 \%$ & 28 \\
\hline Volunteer work (unrelated to COVID-19) & $6.94 \%$ & 20 \\
\hline \multicolumn{3}{|l|}{ Plans for the 2020-2021 academic year } \\
\hline $\begin{array}{l}\text { I planned to apply during the } \\
2020-2021 \text { cycle and still plan to }\end{array}$ & $80.00 \%$ & 68 \\
\hline $\begin{array}{l}\text { I planned to complete a research year } \\
\text { and still plan to }\end{array}$ & $1.18 \%$ & 1 \\
\hline $\begin{array}{l}\text { As a result of the pandemic I now plan to } \\
\text { take a research year }\end{array}$ & $5.88 \%$ & 5 \\
\hline $\begin{array}{l}\text { As a result of the pandemic I will no } \\
\text { longer be taking an intended research } \\
\text { year and will apply in the } 2020-2021 \\
\text { cycle instead }\end{array}$ & $2.35 \%$ & 2 \\
\hline $\begin{array}{l}\text { I am unsure whether my plans will be } \\
\text { changed }\end{array}$ & $7.06 \%$ & 6 \\
\hline Other: & $3.53 \%$ & 3 \\
\hline \multicolumn{3}{|l|}{ USMLE test delays } \\
\hline None & $38.10 \%$ & 40 \\
\hline Step 1 & $1.90 \%$ & 2 \\
\hline Step 2 CK & $27.62 \%$ & 29 \\
\hline Step 2 CS & $32.38 \%$ & 34 \\
\hline \multicolumn{3}{|l|}{ USMLE complete before ERAS deadline } \\
\hline USMLE Step 1 & $50.36 \%$ & 70 \\
\hline USMLE Step 2CK & $34.53 \%$ & 48 \\
\hline USMLE 2CS & $15.11 \%$ & 21 \\
\hline \multicolumn{3}{|l|}{ Core clerkship delays } \\
\hline Yes & $45.35 \%$ & 39 \\
\hline No & $54.65 \%$ & 47 \\
\hline \multicolumn{3}{|l|}{ Home ophthalmology elective delays } \\
\hline Yes & $45.35 \%$ & 39 \\
\hline No & $54.65 \%$ & 47 \\
\hline \multicolumn{3}{|l|}{$\begin{array}{l}\text { Adequate clinical exposure prior to } \\
\text { graduation? }\end{array}$} \\
\hline Yes & $41.86 \%$ & 36 \\
\hline No & $11.63 \%$ & 10 \\
\hline Unsure & $46.51 \%$ & 40 \\
\hline \multicolumn{3}{|l|}{$\begin{array}{l}\text { Participate in a virtual elective outside of } \\
\text { your medical school }\end{array}$} \\
\hline Yes & $10.47 \%$ & 9 \\
\hline No & $53.49 \%$ & 46 \\
\hline Maybe & $36.05 \%$ & 31 \\
\hline
\end{tabular}

Abbreviations: COVID-19, coronavirus disease 2019; USMLE, United States Medical Licensing Examination.

\section{Discussion}

Our results demonstrate that most respondents felt that COVID-19 has affected their application. Concerns over clinical exposure, application strength, and virtual interviews were prominent. These effects manifested in several ways, most consequentially in those respondents who deferred their 2020 application plans.

Applicants were particularly concerned about the changes to the interview process due to COVID-19. About $95.35 \%$ of respondents felt that the shift to virtual interviews will make it difficult to assess programs and vice versa. This uncertainty was highlighted by the findings that respondents are planning on applying to more programs and accepting more interviews due to COVID-19. The SFMatch preemptively capped the number of interviews a student may attend at $20,{ }^{7}$ a choice supported by most applicants. Applicants suggested several ways to make this interview season easier for them. Most felt that videos of the residents, faculty, the city, and possible living areas would help them evaluate a program. Additionally, they felt that there should be adequate informal time where applicants could socialize with residents, such as what might be found at a pre-interview dinner. ${ }^{8}$

A majority of our respondents reported concerns over inadequate clinical exposure. Almost half (45.35\%) reported delays to their core clerkships and ophthalmology electives. We postulate this produces two different anxieties about applicants' future careers. First, applicants may worry that changes to their core clerkships will render them ill prepared for the clinical responsibilities of intern year. Second, as ophthalmology is a specialty that is often underrepresented in preclinical and clinical medical education, ${ }^{9}$ elective exposure is critical for interested students to confirm their interest in the field. Furthermore, advanced electives allow applicants to showcase themselves and acquire critical letters of recommendation. Our results confirmed this concern, with applicants listing letters of recommendation as their top concern about their application this cycle.

COVID-19's effect on applications can also be positive. About $34.88 \%$ of respondents viewed the disruptions of the global pandemic as a boon to their applications. Most applicants from this group (67\%) reported the unexpected free time gave them increased opportunity to engage in research. While it is not possible to ascertain from our results if the potential positive benefits of COVID-19 were evenly distributed, it is possible that the shutdown unfairly benefitted individuals at universities with access to strong ophthalmic research departments, mentors, or other well-established programs.

There are several limitations to this study. First, the study was a self-report survey and thus susceptible to a response bias. Students may have overstated their concern or may be unaware of the realities of the match as they have not experienced it. Second, although the survey was distributed in a variety of avenues, it is likely a majority of respondents discovered our survey through social media or podcasts. However, our demographic results are similar to publicly available information from previous match cycles. ${ }^{10,11}$ Compared with the 2020 cycle, fewer respondents were female (41.6-35\%). ${ }^{11}$ Ethnically, the 
percent of white and Hispanic respondents decreased from 2012 (64-44\% and 9-5.5\%), while the percent increased for Asian (26-41\%) and African American ( $<1-5.5 \%)$ respondents. ${ }^{10}$ In 2020, the largest demographic from was from the South or Southeast (31.9\%), matching the $30 \%$ of respondents to this survey. Third, it is impossible to accurately determine how many individuals received the survey and calculate a response rate. While we assume the total to be 554 (number of applicants from last year's Match), it is probable our survey did not reach every applicant.

\section{Conclusion}

The COVID-19 pandemic has affected every facet of medical education, creating significant uncertainty in medical education and the residency process. Our findings highlight particular concerns for applicants during the 2020 to 2021 ophthalmology residency interview cycle and some suggestions for how to begin to address these issues.

\section{Authors' Contributions}

All authors have contributed substantially to the conception and design of the work, have drafted and revised the manuscript critically, have final approval of the final version, and agree to be accountable for all aspects of the work.

\section{Financial Support}

This publication was supported by the Yale School of Medicine Medical Student Fellowship.

Bascom Palmer is supported by NIH Center Core Grant P30EY014801, Research to Prevent Blindness Unrestricted Grant.

\section{Conflict of Interest}

Mr. Steren reports other from Yale Medical Student Fellowship, outside the submitted work. Dr. Sridhar reports grants from NIH, outside the submitted work.

\section{References}

1 Important Guidance for Medical Students on Clinical Rotations During the Coronavirus (COVID-19) Outbreak | AAMC. Accessed July 17, 2020 from: https://www.aamc.org/news-insights/pressreleases/important-guidance-medical-students-clinical-rotationsduring-coronavirus-covid-19-outbreak

2 The Impact of the COVID-19 Pandemic on Outpatient Visits. A Rebound Emerges | Commonwealth Fund Accessed July 17, 2020 from: https://www.commonwealthfund.org/publications/2020/ apr/impact-covid-19-outpatient-visits

3 Recommendations for urgent and nonurgent patient care - American Academy of Ophthalmology. Accessed July 17, 2020 from: https://www.aao.org/headline/new-recommendations-urgentnonurgent-patient-care

4 Ophthalmology Quillen DA, Siatkowski RM, Feldon Son behalf of the Association of University Professors of Ophthalmology. COVID-19 and the ophthalmology match. Ophthalmology 2020. Doi: $10.1016 /$ j.ophtha.2020.07.012

5 Final Report and Recommendations for Medical Education Institutions of LCME-Accredited, U.S. Osteopathic, and Non-U.S. Medical School Applicants The Coalition for Physician Accountability's Work Group on Medical Students in the Class of 2021 Moving Across Institutions for Post Graduate Training. Available at aamc.org

6 Ophthalmology Match Timeline for 2020-2021. Accessed July 17, 2020 from: https://aupo.org/system/files/resources/2020-05/ AUPO-SFMatch-Timeline-2021_1.pdf

72021 Ophthalmology Match Updates. Accessed July 17, 2020 from: https://aupo.org/system/files/resources/2020-05/AUPO 2021 Ophthalmology Match Statement_5.8.20.pdf

8 Duong AT, VanTassel SH, Alzaga Fernandez AG, et al. Medical education and path to residency in ophthalmology in the COVID-19 Era: perspective from medical student educators. Ophthalmology 2020;0 (00):S0161-6420(20)30724-7. Doi: 10.1016/j.ophtha.2020.07.036

9 Moxon NR, Goyal A, Giaconi JA, et al. The state of ophthalmology medical student education in the United States: an update. Ophthalmology 2020; (May):S0161-6420(20)30425-5. Doi: 10.1016/j. ophtha.2020.05.001

10 Yousuf SJ, Kwagyan J, Jones LS. Applicants' choice of an ophthalmology residency program. Ophthalmology 2013;120(02):423-427

11 Venincasa MJ, Cai LZ, Gedde SJ, Uhler T, Sridhar J. Current applicant perceptions of the ophthalmology residency match. JAMA Ophthalmol 2020;138(05):460-466 